\title{
Vorwort zur III. Auflage.
}

In der Anordnung des Stoffes und im allgemeinen Teil ist nichts geändert, dagegen bei mehreren Luxationsformen neue Erfahrungen der Beobachter hinzugefügt. Ich bin den Herren Collegen, welche mich durch freundliche Zusendung von SeparatAbdrücken unterstützt haben, zu Dank verpflichtet, da ich anderenfalls nur die oft ungenauen Referate ihrer Arbeiten hätte benutzen können.

\section{Vorwort zur IV. Auflage.}

In der vorliegenden IV. Auflage habe ich die congenitalen Hüftgelenk-Luxationen genauer besprochen, als wie bisher. Von Rechtswegen gehören dieselben eigentlich nicht in ein Compendium der Lehre von den frischen traumatischen Luxationen. Die grosse Wichtigkeit, welche ganz besonders in therapeutischer Beziehung die Luxatio coxae congenita in den letzten Jahren erhalten hat, rechtfertigt aber wohl den Versuch einer kurzen Darstellung sowohl für Aerzte als auch für Studirende. Für die Ersteren wird es sich im Wesentlichen darum handeln aus den bisherigen Erfahrungen einen Wegweiser zu geben für die jeweilig einzuschlagende Behandlung und die Prognose möglichst eingehend zu besprechen wie sie sich nach dem heutigen Stande der Therapie gestaltet hat, denn es ist für den Arzt schon jetzt nicht mehr leicht sich aus der bereits sehr umfangreichen Litteratur ein genaues Bild über die Vortheile und event. Nachtheile der blutigen oder unblutigen Behandlung zu verschaffen. Den Studirenden muss vor allen Dingen die pathologische Anatomie erläutert werden, die erst durch die auf dem 
Wege der Operation freigelegten Gelenkveränderungen bekannt geworden ist.

Ich habe mich selbstverständlich bei der Schilderung der betreffenden Krankheitsbilder in der Hauptsache durchaus nach den Arbeiten von Paci, Hoffa und Lorenz gerichtet, die uns erst die Wege gelehrt haben, welche bei der Behandlung des Leidens zu gehen sind. Auf die vielen Arbeiten resp. casuististischen Veröffentlichungen von Broca, Kirmisson, Dolega, Leser, Bradford, Thilo, Ogston, Teufel, Rosenfeld, Schüssler, König, Schede, Mikulicz, Buckminster Brown, Lampugnani, Denucé, Barwell, Karewski, Heusner u. a. einzugehen, würde zu weit geführt haben. Wer sich speciell mit dem vorliegenden Thema beschäftigen will, muss die Arbeiten der genannten Autoren studiren. 